\title{
Potential Molecular Players Against to SARS-CoV-2: A Glyco-Perspective
}

Tugrul B*, Balcan E and Oztel Z

Manisa Celal Bayar University, Department of Biology, Molecular Biology Section, Manisa, Turkey

${ }^{*}$ Corresponding author: Tugrul B, Manisa Celal Bayar University, Faculty of Arts and Sciences, Şehit Prof. Dr. İlhan VARANK Campus, Manisa, Turkey, Tel: +90 236 2013280, E-mail: berrin.tugrul@yahoo.com

Citation: Tugrul B, Balcan E, Oztel Z (2021) Potential Molecular Players Against to SARS-CoV-2: A Glyco-Perspective. J Cell Biol Histol 4(1): 101. doi: 10.15744/2638-082X.4.101

Received Date: April 19, 2021 Accepted Date: May 19, 2021 Published Date: May 21, 2021

\begin{abstract}
COVID-19 is caused by SARS-CoV-2 and is associated with the increasing number of cases and deaths and has been declared a pandemic by WHO. The treatment strategy focused on preventing the $\mathrm{S}$ protein from binding and penetrating the ACE-2 receptor. In addition, $S$ protein-related molecules such as peptides, blockers, and inhibitors that inhibit $S$ protein cleavage are considered candidate therapeutics. However, the major hurdle in the development of anti-viral therapy appears to be glycosylated components of a virus. Host-derived glycosylated molecules of a particular virus can protect them from immune attack and increase their virulence with masking effects. In this review, various aspects of glycans regarding virus-host interactions and new therapeutic concepts on the glycosylation machinery are discussed.
\end{abstract}

Keywords: SARS-CoV-2; S protein; Glycosylation; Furin; TMPRSS2

List of abbreviations: ACE-2: Angiotensin Converting Enzyme 2 Receptor; ARDS: Acute Respiratory Distress Syndrome; CD: Connector Domain; CH: Central Helix; COVID-19: Coronavirus Disease-19; CT: Cytoplasmic Tail; CTD: C-terminal Domain; E: Envelope; ER: Endoplasmic Reticulum; ERGIC: Endoplasmic Reticulum-Golgi Intermediate Compartment; FP: Fusion Peptide; Gals: Galectins; MBL: Mannose-Binding Lectin; HIV-1: Human Immunodeficiency Virus Type 1; HR1/2: Heptad Repeat 1/2; HR1: Heptad Repeat 1; HR2: Heptad Peptid 2; IFP: Internal Fusion Peptide; M: Membrane; MERS-CoV: Middle East Respiratory Syndrome Coronavirus; MHC: Major Histocompatibility Complex; N: Nucleocapsid; NSPs: Nonstructural Proteins; NTD: N-terminal Domain; ORFs: Open Reading Frames; PTMs: Post Translational Modifications; RBD: Receptor-Binding Domain; RdRp: RNA Polymerase; S: Spike Protein; S1: Subunit 1 of Spike Protein; S2: Subunit 2 of Spike Protein; SARS-CoV: Severe Acute Respiratory Syndrome Coronavirus; SARS-CoV 2: Severe Acute Respiratory Syndrome Coronavirus 2; SP: Signal Peptide; TM: Transmembrane; TMPRSS2: Transmembrane Protease Serine 2; WHO: World Health Organization 


\section{Introduction}

Most patients who are suffering from COVID 19 caused by the SARS-CoV2 virus, which is included in the betacoronavirus genus, show mild or moderate symptoms. $20 \%$ of patients have a phenotype caused by other coronaviruses SARS-CoV and MERS-CoV with high virulence [1-4]. They have pneumonia, ARDS and sepsis [5]. Recent findings shown that, severe COVID-19 patients are strongly associated with a manifestation of lymphopenia, decreased monocytes, eosinophils and basophils, increased neutrophil count $[4,6,7]$. However, in many cases, hyperimmune reactions were conduct to worst results. For instance, as a result of viral infection the innate immune system of most patients with severe COVID-19 release many pro-inflammatory cytokines and chemokines into circulation. The clinical reflection of this intense reaction so-called 'cytokine storm' is seemed as frequently alveolar damage resulting the respiratory failure [4,6-10].

Current approaches on the development of novel therapeutics have been focused on the molecules that regulate of the viral entry. During the viral infection, the S1 subunit of the trimeric S glycoprotein of SARS-CoV-2 recognize its host receptor- ACE2, a type I membrane receptor expressed in various tissues including lungs, heart, kidney and intestine [11,12], while the other subunit, S2, enables fusion of viral and host cell membranes. Most recently, it has been reported that ACE-2-mediated virus internalization is regulated by a serine protease, TMPRSS2 [13]. When SARS-CoV-2 and SARS-CoV were compared in terms of genome and protein similarity, it was revealed that there was similarity between their genome (79\%) and protein structure (95-100\%). However, it has been determined that the feature specific to SARS-CoV2, but not in other coronaviruses is the furin cleaveage region between the spike protein S1 and S2. Phylogenetic analysis showed that the multibasic amino acid (PRRAR) sequence was included in the relevant segment in the new virus [14] The study of Wrobel et al. shows that the presence of the furin cleavage site in the S protein of SARS-CoV-2 facilitates the conformational change required for the exposure of the RBD domain and binding of the protein to host surface receptors [15].

While functional significance of glycobiology has been well-known for about 40 years, its revolutionary potential on molecular cell biology has been unfolded for last two decades. Emerging advances in glycobiology, and its informatics platforms, glycomics and glycoproteomics, have been enabled it central to development of new strategies for therapeutic and diagnostic purposes [16]. Although different vaccines have been developed against SARS-CoV-2, a more effective treatment strategy has not been developed yet. Glycosylation of surface proteins, one of the virus structural proteins, has an effect on viral entry, impairment of the host's adaptive immunity, and enhancement of infectivity. One of the issues to be clarified is how the proteins of the virus, especially the $S$ protein, are modified by glycosylation mechanisms. In addition, the interaction of the spike protein with ACE2 and furin is extremely important for viral entry. Therefore, revealing the S protein and ACE2 glycosylation profiles and and demonstrating the effect of these glycosylations on virus-host interaction may provide the development of new effective treatment strategies against infection.

In this review, we attempt to summarize current knowledge of mechanism(s) of SARS-CoV-2 infection in terms of glycoperspective. We also mainly focused on the potential glycobiological treatment strategies on the viral infections will be scrutinized.

\section{Genome and Proteins of SARS-CoV-2}

In the recent studies has been shown that the genome of SARS CoV-2 (NCBI Reference Sequence: NC_045512.2) (Figure 1) is quite similar to the genome of SARS-CoV-1. (NCBI Reference sequence: NC_004718.3) [17-19]. SARS CoV-2 is an enveloped, positivesense single-stranded RNA virus and its RNA genome encodes structural and NSPs [20]. SARS-CoV-2 has 11 genes with 11 ORFs. 1. ORF1ab gene expresses 16 NSPs. NSP1 induces host mRNA cleavage. NSP2 binds to host prohibitin 1 and prohibitin 2 . NSP3, papain like proteinase, releases NSP1, NSP2 and NSP3 and significant for viral activity. NSP4 which contains transmembrane domain 2 forms an interaction NSP3 and this interaction plays a significant role in viral replication. NSP5, 3C-like proteinase, cleaves at 11 sites of NSP polyprotein. NSP6, putative transmembrane domain, participates in autophagosome formation. NSP7 
plays a role in the interaction of NSP8 and NSP12. NSP8 makes heterodimer with NSP7, then NSP12 joins the heterodimer. Thus, RNA polymerase complex is formed. NSP9 binds to helicase cellular protein and this binding is necessary for viral replication. NSP10 may stimulate NSP16, a 2'-O-methyl-transferase. The activity of NSP11 is not yet known. NSP12, RNA dependent RNA polymerase (RdRp), copies viral RNA. NSP13 has helicase activity. NSP14 has $3^{\prime}$ to $5^{\prime}$ endonuclease and N/-methyltransferase activities. NSP15 is endoribonuclease and provides escape from the host immune system. NSP16, 2'-O-Ribose-Methyltransferase, methylates Adenine. Thus, mRNA is protected from host immune system. 2. ORF2 gene expresses $\mathrm{S}$ protein which is a glycoprotein and one of the structural proteins of the virus. S protein provides that SARS-CoV-2 attach to host cell membrane receptor. 3. ORF3a gene expresses an ion channel protein related to NLRP3 inflammasome activation. The interaction of this protein with other related proteins results in caspase 1 and IL-1 $\beta$ maturation. 4. ORF4 gene encodes the E protein of the virus. E protein is one of the structural proteins and has the multiple viral functions (e. g. viral assembly, viral replication, viral pathogenesis). 5. ORF5 gene expresses $M$ protein which is structural protein. The role of M protein is viral assembly. $\mathbf{6}$. ORF6 gene encodes an accessory protein of virus. It has been shown that this protein has the function of viral pathogenesis. 7. ORF7a gene expresses a type I transmembrane protein which is accessory protein. 8. ORF7b gene encodes accessory protein and is expressed in virus-infected cells. 9. ORF8 gene expresses ORF8 protein. 10. ORF9, a structural gene, encodes nucleocapsid (N) protein. 11 . ORF10 gene's function is unknown. Of NSP proteins of SARS-CoV-2, NSP3, NSP5, NSP12 and NSP15 have been suggested to be antiviral drug targets [21].

SARS-CoV2 genome (29 $903 \mathrm{nt})$

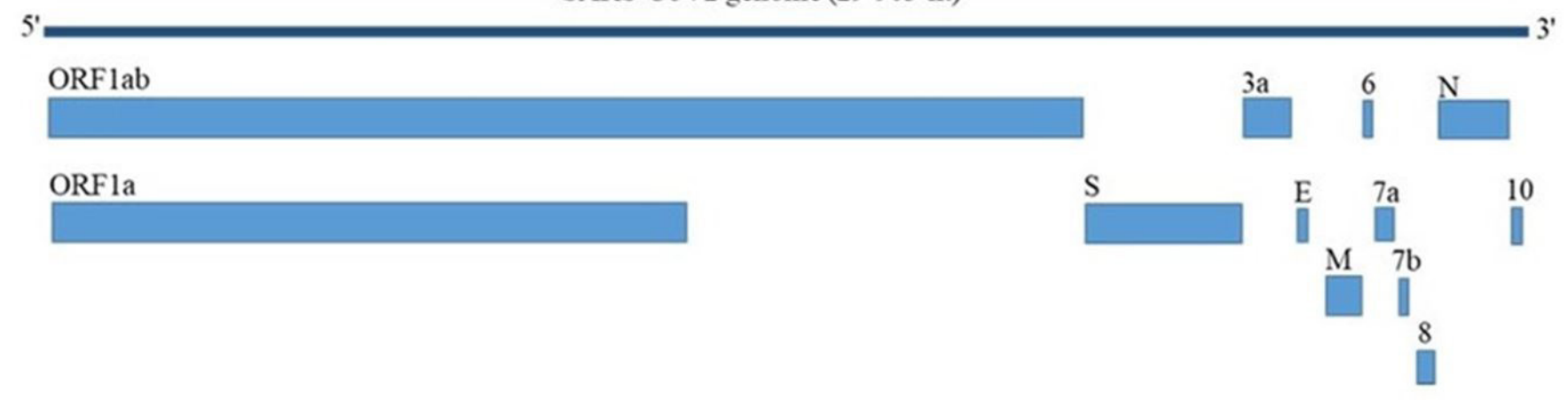

Figure 1: The structure of SARS-CoV2 genome [22]

\section{Host Cell Infection with SARS-CoV-2}

The binding of viral S proteins to ACE-2 is the first step of coronavirus infection [23]. SARS-CoV-2 S protein (Figure 2) consists of two subunits (S1 and S2) containing SP, N- NTD, RBD, FP, IFP, HR1/2, and TM domains [24]. The proteolytic activation of S protein is essential for viral entry. Cleavage of S protein at the extremely cleavable site that is located at S1/S2 boundary is mediated by furin and is required for binding of RBD of S1 to ACE-2 [25]. In addition to binding, activation of the viral S protein by the host TMPRSS2 is required for virus-cell membrane fusion [26]. The S2 subunit consists of FP, HR1 and HR2 domains. The S2 subunit folds in on itself, bringing HR1 and HR2 domain together. This leads to membrane fusion and then the viral nucleocapsid delivers into the cytoplasm of host cell [23]. The viral RNA is replicated and ORFs are translated to produce viral proteins. Virion assembly occurs in the (ERGIC) (Figure 3). In order to proper virion assembly, viral proteins should undergo a series organized modifications. PTMs of proteins are vital mechanisms for a cell. The main role of PTMs is to functionally modulate proteins with various covalent modifications including phosphorylation, ubiquitination, methylation, acetylation and glycosylation [27]. It is widely confirmed that modification of many viral proteins is depend on host's PTM machinery [28,29]. The most prominent PTMs of coronaviruses are glycosylation, palmitoylation and phosphorylation of viral proteins [29,30]. Since most of surface proteins of SARS-CoV-2 have been glycosylated, and glycans regulate many cellular processes, glycosylation machinery is essential for the viral functions $[31,32]$. 
S2' Cleavage (816 residue)

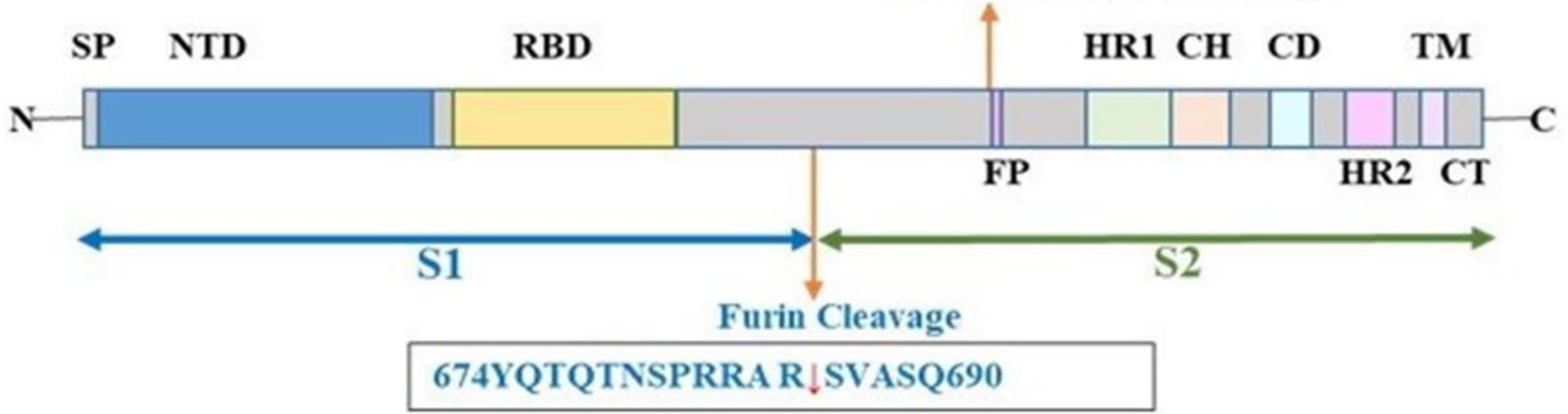

Figure 2: The structure and furin and S2'cleavage sites of SARS-CoV2 spike protein

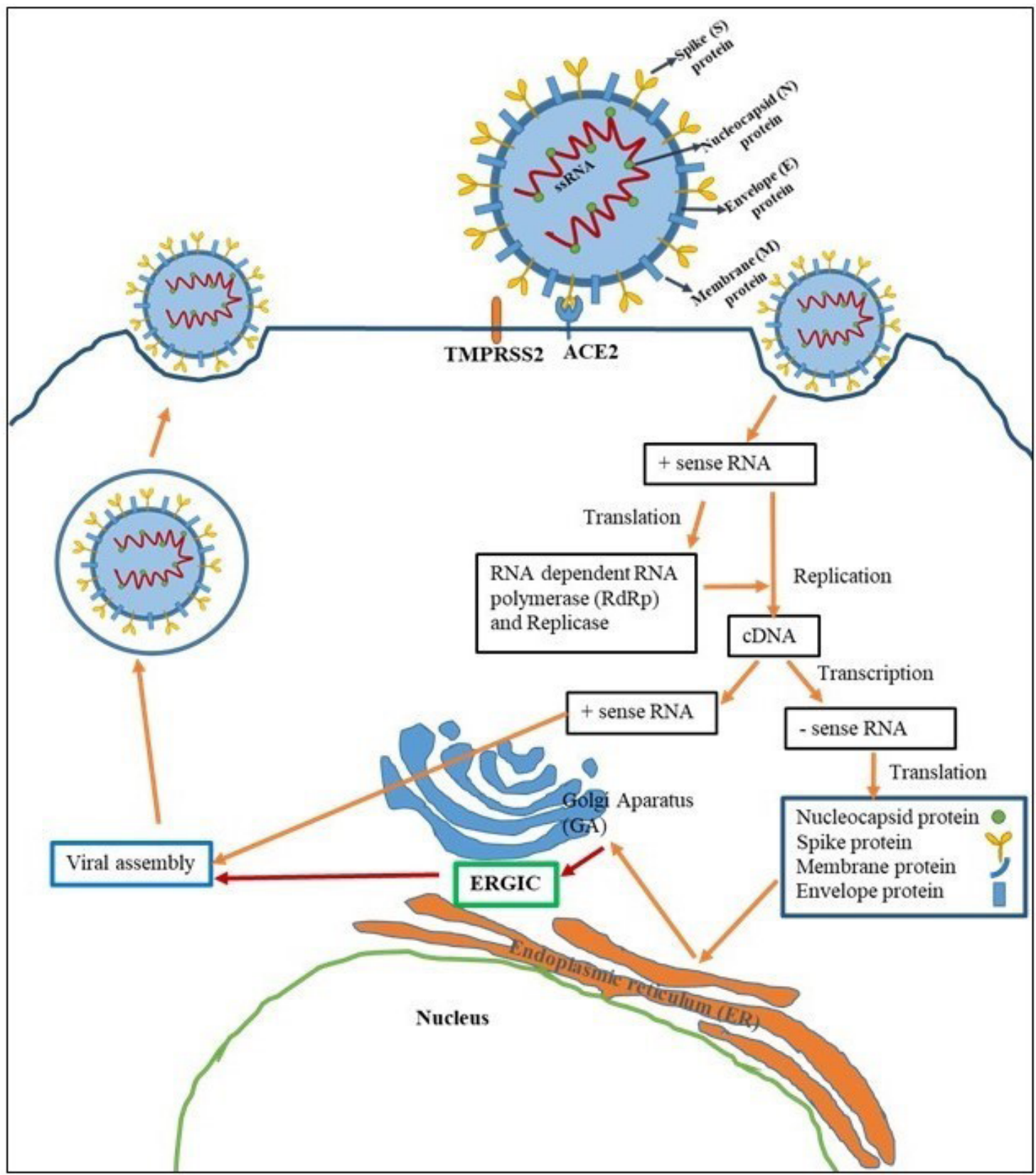

Figure 3: Life cycle of SARS-CoV2 


\section{S Protein}

It has been found in previous studies that coronavirus S proteins covered with $\mathrm{N}$ glycosylated motifs [33] that are probable associated with folding of $S$ proteins appositely, priming by host cell proteases as well as modulation of antibody recognition [34]. Together with S1 and S2 subunits, the spike protein of SARS-CoV-2 has 22 [34] known N-linked glycosylation sites, 20 of them are also found in S protein of SARS-CoV-1 [35,36]. At the same time, some glycans in S1 and S2 subunits show homology between SARS-C OV-1 and -2. Receptor binding domain (RBD) of S1 subunit, which is located between residues 303 and 537 [30], is prominent variation site in coronavirus genome [37,38]. More recently two conflicting reports have been published on the structural analysis of RBD. It has been revealed that the most substantial amino acids of RBD for ACE-2 binding in SARS-CoV-2 are L455, F486, Q493, S494, N501 and Y505. However, only one of these residues, Y505, is similar which corresponding region in SARS-CoV-1 [39]. Nevertheless, Zhao's group declared that the number of amino acids in SARS-CoV-1 RGB that are interfere the binding to ACE-2 is 16 and 8 of them are conserved in SARS-CoV-2 [40]. Although the strong structural similarity between SARSCoV-1 and 2 (approx. 74\%) has been revealed, it has most recently been shown that SARS-CoV-2 RBD has larger surface area than 1 and each glycosylation site of S protein in SARS-CoV-2 comprise $22 \mathrm{~N}$-glycans [41] and trace levels of O-linked glycosylation at Thr323/Ser325 (T323/S325) [42] (Table 1). Among these glycosylation sites, RBD comprises only two [40] or three [30,43,44] of them. The revealing of SARS-CoV-2 glycan profiles is extremely important in terms of vaccine and treatment strategies.

\begin{tabular}{|c|c|c|c|}
\hline Glycolysation & S Protein Domain & Residue & Glycan type \\
\hline \multirow{22}{*}{ N-linked glycolysation } & \multirow{8}{*}{ NTD } & N17 & complex \\
\hline & & N61 & oligomannose- and complex mixture \\
\hline & & N74 & complex \\
\hline & & N122 & oligomannose- and complex mixture \\
\hline & & N149 & complex \\
\hline & & N165 & complex \\
\hline & & N234 & oligomannose \\
\hline & & N282 & complex \\
\hline & \multirow{2}{*}{$\mathrm{RBD}$} & N331 & complex \\
\hline & & N343 & complex \\
\hline & \multirow{6}{*}{$\mathrm{RBD}$ to $\mathrm{FP}$} & N603 & oligomannose- and complex mixture \\
\hline & & N616 & complex \\
\hline & & N657 & complex \\
\hline & & N709 & oligomannose \\
\hline & & N717 & oligomannose- and complex mixture \\
\hline & & N801 & oligomannose- and complex mixture \\
\hline & $\mathrm{CH}$ to $\mathrm{CD}$ & N1074 & oligomannose- and complex mixture \\
\hline & \multirow{2}{*}{$\mathrm{CD}$} & N1098 & complex \\
\hline & & N1134 & complex \\
\hline & \multirow{3}{*}{$\mathrm{CD}$ to $\mathrm{TM}$} & N1158 & complex \\
\hline & & N1173 & complex \\
\hline & & N1194 & complex \\
\hline \multirow{2}{*}{ O-linked glycolysation } & $\mathrm{RBD}$ & T323 & \\
\hline & $\mathrm{RBD}$ & S325 & \\
\hline
\end{tabular}

Table 1: Glycolysation profile of SARS CoV2 spike protein [42] 
$\mathrm{N}$-glycan microheterogeneity, the diversity of N-glycans localizing glycosylation sites of a protein, is essential for orchestrating the protein function. Given the trimeric structure of $\mathrm{S}$ protein, it has been conceivable that much site specific $\mathrm{N}$-glycan microheterogeneity may influence function of the S protein which is particularly substantial for anti-viral vaccine development trials [42]. N-linked glycan motifs interfere many cellular events such as inflammatory responses, as well as protein folding and transport [45]. For instance, a phenylalanine residue before the Asparagine-XXX-Serine/Threonine sequon can interacts with first GlcNAc of the N-linked glycan during the glycosylation in ER and the Golgi and eventually can change site-specific N-glycan profile of the protein and also increase the glycosylation efficiency [46-48]. The glycosylation pattern of viral proteins highly depends on glycosylation processes of the host [49]. In SARS-CoV-2 and other human coronaviruses, but not in SARS-CoV-1related ones, the junctional area of S1 and S2 holds an arginine-rich region that is cleaved at R685-S686 by the cellular protease furin [50] (Figure 2). This polybasic region includes three predicted O-glycosylation sites, S673, T678 and S686, flanking the S1/ $\mathrm{S} 2$ cleavage region of the $\mathrm{S}$ protein. Although the polybasic region would be essential for cleavage of $\mathrm{S}$ protein [50], the functional enigma of the predicted O-glycans has not yet been unraveled. Although, the polybasic cleavage site in SARS-CoV-2 is absent in SARS-CoV-1 and other related bat viruses, protease-dependent cleavage is essential for proteolytic maturation of class I viral fusion proteins, that is contribute the fusion potential of virus [51]. More interestingly, O-glycans are quite close the polybasic site in SARS-CoV-2, even the 3rd O-glycan-harbored S (686) is flanked the cleavage site (R687). However, only S336 has predicted $\mathrm{O}$-glycosylation site in S1 of SARS-CoV-1. These results suggest that O-glycan motifs of polybasic cleave site create a masking effect through covering the epitopes of spike protein as previously reported for HIV-1 [52], Ebola [53], Epstein-barr [54], hepatitis C [55], arenavirus [56] and human coronavirus NL63 [57] glycoprotein epitopes. It seems that the predicted O-glycosylation sites that extremely flanked the polybasic cleavage region in S protein may new target for anti-SARS-CoV-2 glycotheraphy.

\section{ACE-2, Furin, and TMPRSS2}

It should not be surprised that the some of glycoforms that occupy the glycosylation sites in the glycomolecules of host cells, such as furin, ACE-2 and serine protease TMPRSS2, can responsible for virus-host interactions, viral invasion, or activation of envelope proteins such as spike of SARS-CoV-2. Although, in a previous study, Zhou and his colleagues has shown that impairment of ACE2 glycosylation machinery can induce to blocking of SARS-CoV-1 entry [58], the glycans in ACE2, furin and / or TMPRSS2 appear to play an important role in SARS-CoV2 infection.

The extracellular domain of the ACE2 receptor contains $\mathrm{N}$ and $\mathrm{O}$ glycalization sites. There are several O-glycosylated regions and seven N-glycosylated regions including N53, N90, N103, N322, N432, N456 and N690 [12,59]. N90 and N322 of these glycosylation sites have been shown to be important in binding ACE2 to the SARS CoV2 spike protein [60].

The family of proprotein convertases, calcium-dependent serine proteases, are convert precursor proteins into their active forms [61]. As a member of this family, furin is found in mainly epithelial cells, fibroblasts and T-cells as well as endothelial cells of oral mucosa, but it shows a decreased expression profile in B lymphocytes [57]. The spike protein of SRAS-CoV2 has cleavage sites recognized by host cell proteases and required for binding to ACE2. The first cleavage is carried out by the host protease furin (Figure 2) from the region between the S1/S2 subunits boundary of the S protein [25]. Compounds that inhibit furin would be a promising site for COVID-19 treatment [62]. A series of furin inhibitors such as the 4-amidinobenzylamide-derived inhibitors [63], 4-(guanidinomethyl) phenylacetyl-Arg-Val-Arg-4-amidinobenzylamide [64] have been submitted previously, however the knowledge on the unwanted side effects of these compounds remain not being clear $[65,66]$. Glycan motifs of furin have not been evaluated as target structures for anti-viral drug or vaccine developments so far. Human furin harbours 3 predicted N-glycosylation, N378, N440 and N553, and 33 O-glycosylation sites at different positions (http://www.cbs.dtu.dk/services/NetOGlyc/). Due to their structural, biochemical and conformational dynamics, glycan motifs not only on the viral envelope, but also occupying on the host cells might be prominent motifs for drug binding. 
Human type-II transmembrane serine protease, TMPRSS2, is colocalized with ACE-2 (Figure 3) in the surface of epithelial cells and the cleavages of ACE- 2 by TMPRSS2 augment the viral fusion $[13,67,68]$. Previous studies indicated that in the surface of type II pneumocytes and alveolar macrophages, TMPRSS2 co-expressed with 2-6 linked sialic acids that are cellular receptors for influenza virus HA and interfere with $\mathrm{N}$-glycosylation machinery by an unknown mechanism [69,70]. In addition, altered doses of TMPRSS2 have different effects on ACE-2. For instance, low dose of TMPRSS2 converts ACE-2 from an $\sim 130 \mathrm{kDa}$ to an 115 form whereas as the amount of TMPRSS2 increases, the effect becomes larger [67]. This finding may be evidence that the cell surface glycan motifs are one of the major determinants in viral invasion. TMPRSS2, has two putative N-, N213 and 249 [71], and ten Oglycosylation sites (unpublished data which has reached by using NetOGlyc server, http://www.cbs.dtu.dk/services/NetOGlyc/). However, it has not yet been determined whether these glycosylation sites are involved in the SARS-CoV-2 infection.

In conclusion it can be hypothesized that TMPRSS2 can augment entry of SARS-CoV-2 through converting the glycosylation profile of ACE-2. However, this argument needs further research.

\section{Lectins and Galectins}

Lectins are a class of specialized glycan-binding proteins which are widely distributed in nature. Apart from antibodies and enzymes, these proteins selectively and reversely recognize carbohydrate molecules through their "carbohydrate recognition motifs" and thereby involve various cellular biological events [72]. On the other hand, Gals are a family of animal lectins that recognize to $\beta$-galactoside. They bind cell surface and matrix glycans and regulate many cellular processes [73]. In viral biology, galectins and lectins have various effects such as virus-host interactions, increasing or inhibition of infection and occurring of innate and adaptive immune responses [74]. For instance, DC-SIGN, a C-type lectin found on the surface of dendritic cells, can recognize glycosylated S protein of SARS CoV and facilitate the viral infection through S protein-ACE-2 binding. Similarly, the recognition of S protein by host's mannose-binding lectin can cause an innate immune response against SARS CoV [75].

Due to their multivalency, in pathogen-host interactions, galectins play in promoting or inhibiting viral infection. Gals can bind to glycan motifs on both virus and host cell surface. According to their binding specificity, either viral infection is prevented or triggered by adhesion to target cell. Therefore, revealing the structure of glycans in viral glycoproteins is important to determine the potential pro- or anti- viral effect of galectins bound to these glycans [76]. Recent reports indicate that Gal-1, Gal-3 and Gal-9 are major galectins that regulate the viral infection. Gal-1, Gal-3 and Gal-9 are major galectins that regulate the viral infection have been reported [76]. For instance, Gal-1 facilitates to gp120 (viral glycoprotein) - CD4+T cell binding in HIV-1. So prevention of interaction between gp120 and Gal-1 might be promised new approaches to HIV-1 therapy [77]. Gal-3 is a potent modulator of cell death in many cell types including T cells, mast cells as well as hepatic stellat cells. It has been suggested that Gal-3's further induction of cell death in HIV-infected cells may be due to the glycosylation change at the Gal-3 receptor [78]. Since galectins have different effects during viral infection, depending on their interaction with viral or host cell molecules, their expression levels, and their types, galectins can be prominent targets for antiviral therapy.

The fact that galectins have different effects depending on their interaction with viral or host cell molecules during viral infection, their expression levels and the type of galectin, makes them a new target in therapy as immune modulators. Mostly, CTD of S1 subunit binds to proteins however NTD prefers extracellular sugars. It has been suggested that the interaction between CTD of SARS CoV-2 spike protein and host ACE2 is depend on galectin-like NTD [79]. More recently, a new type of NTD domain of the SARS CoV-2 spike protein that binds gangliosides has been investigated [80]. This observation indicates that ganglioside associated cell surface sialic acids are crucial for viral entry as well as ACE-2. More interestingly, the spike proteins have similar structures with Gal-3 [81]. Therefore, Gal-3 inhibition that can disrupt the binding of SARS CoV-2 NTD to ganglioside on the cell surface might a new approach for the treatment of COVID-19 [79]. 


\section{Carbohydrate Mimetics}

There are two potential targets of anti-viral treatment: viral and cellular components. In both cases the ER and Golgi apparatus play essential roles such as glycosylation machinery, modification of nascent proteins by removing and addition of sugars to core oligosaccharides. ER is also a dynamic organelle for protein quality control that is needful for proper folding, sorting and secretion of newly synthesized proteins. In this complicated system, the glycan motifs introduced as "markers" that are recognized by a series of ER membrane bound lectin chaperons and enzymes such as calnexin, calreticulin, glucosidase I and II [82,83].

During the protein synthesis, all growing glycoprotein harbor three glucose residues at the terminals of their $\mathrm{N}$-linked glycans. Two of three terminal glucoses of improperly folded glycoproteins removed by glucosidases and remaining single glucose serve as a label for recognized by ER membrane-associated lectins, calnexin and calreticulin, hereby incompletely folded glycoproteins containing monoglucosylated N-glycans are arrested in the ER until the glucose is removed by a specific glucosydase. A glycosyl transferase decides whether the protein is properly folded. Improperly folded proteins return to ER and a new glucose is added and the cycle, so-called calnexin / calreticulin cycle, repeats until the glycoprotein has properly folded [82].

A group of carbohydrate mimetics where the substitution of the cyclic oxygen by a nitrogen, iminosugars are potent candidate compounds for the development new anti-viral strategies [84], due to their inhibitor effects on the glucosidase I and II, which mediators of $\mathrm{N}$-glycan processing through the entry of glycoproteins to calnexin/calreticulin cycle [82]. The anti-viral properties of these sugar mimetics have been reported in a series of viral infections such as dengue virus, influenza virus, hepatitis $\mathrm{C}$ virus and human immunodeficiency virus and zika virus [84]. The impairment of viral envelope glycoprotein folding due to failure of glucose trimming can reduce of virus-host cell contacts $[85,86]$. The key point in the anti-viral effects of iminosugars is that the all enveloped viruses have extensively glycosylated proteins that are strongly subjected of calnexin/calreticulin cycle for proper folding. Recent studies indicated that inhibition is strongly based on the iminosugar structure. For instance novel Deoxynojirimycin neoglyco conjugates containing alkyl chains have shown efficiently inhibited a series of glucosidases [85,87]. However, during the chronic viral infection, glucosidase inhibition might lead T-cell activation regarding to the increasing of presentation of peptide epitopes of virus, if given glucosidase inhibitor retains MHC class I in the ER [88].

\section{Should Sialic Acids Be Sufficient for Viral Spread?}

The answer of this question has not been cleared so far. Previous reports indicated that hemagglutinin antigen of influenza virus is binds sialic acid harboring cell surface molecules with highly affinity and this contact leads viral transduction [89]. Similarly, MERS-CoV have also considered that $\mathrm{S}$ glycoprotein shows binding function to cellular sialic acids [90]. These findings can be assumed as sialic acids can mediate SARS-CoV-2 infection [91]. Similar to sialic acid modifications, removing of sialic acids by neuraminidases and mutations in S protein can block viral attachment [91] and hence this can be a potent diagnostic marker for detection of SARS-CoV-2 [92].

\section{Conclusion}

The glycan repertoires harbored in most of the viral and cellular glycoproteins serve as signals for the viral invasion processes, such as fusion and endocytosis. In these processes, glycans contribute to viral invasion by a series strategies including shedding of viral glycoproteins from infected cells as snares for the host immune system, escaping from host immune system using with the mimicked glycans (glycomimetics), binding to glycan-recognizing motifs of the host cell or binding to glycan motifs of the host cell via glycan binding receptors such as viral lectins $[93,94]$. These multi-faced attempts of viruses may explain why we should highlight the glycans in the development of anti-viral strategies. The most popular example of glycan-based drugs are engineered glycan moieties, influenza therapeutics zanamivir (Relenza) [95] and oseltamivir (Tamiflu) [96] which are inhibitor of neuraminidase activity, an enzyme that is essential for virus replication. Although the significance of glycans, synthetic glycans and glycomimetics 
have recognized, a glyco-strategy for SARS-CoV-2 has still not yet been comprehensively investigated. However, it would appear that engineering glycans will most prominent candidate for the clinical trials to viruses as well as engineered cell surface proteins. However, the main issue is that most of the glycomimetics cannot compete with their natural ligands with sufficient avidity. Consequently multivalent alternative compounds such as polymers and nanoparticles might solve this paucity [97].

\section{Conflict of Interest}

No conflict of interest or common interest has been declared by the authors. 


\section{References}

1. Gorbalenya AE, Baker SC, Baric RS, de Groot RJ, Drosten C, et al. (2020) Coronaviridae Study Group of the International Committee on Taxonomy of V. The Species Severe Acute Respiratory Syndrome-Related Coronavirus: Classifying 2019-Ncov and Naming It SARS-CoV-2. Nat Microbiol 5: 536-44.

2. Hirano T, Murakami M (2020) COVID-19: A New Virus, but a Familiar Receptor and Cytokine Release Syndrome. Immunity 52: 731-3.

3. de Wit E, van Doremalen N, Falzarano D, Munster VJ (2016) SARS and MERS: Recent Insights into Emerging Coronaviruses. Nat Rev Microbiol 14: 523-34.

4. Hirano T, Murakami M (2020) COVID-19: A New Virus, but a Familiar Receptor and Cytokine Release Syndrome. Immunity 52: 731-3.

5. Wu Z, McGoogan JM (2020) Characteristics of and Important Lessons from the Coronavirus Disease 2019 (COVID-19) Outbreak in China: Summary of a Report of 72314 Cases from the Chinese Center for Disease Control and Prevention. JAMA 323: $1239-42$.

6. Qin C, Zhou L, Hu Z, Zhang S, Yang S, et al. (2020) Dysregulation of Immune Response in Patients with Coronavirus 2019 (COVID-19) in Wuhan, China. Clin Infect Dis. 71: 762-8.

7. Xu Z, Shi L, Wang Y, Zhang J, Huang L, et al. (2020) Pathological Findings of COVID-19 Associated with Acute Respiratory Distress Syndrome. Lancet Respir Med 8: 420-2.

8. Ramos-Casals M, Brito-Zeron P, Lopez-Guillermo A, Khamashta MA, Bosch X (2014) Adult Haemophagocytic Syndrome. Lancet 383: 1503-16.

9. Schoeman D, Fielding BC (2019) Coronavirus Envelope Protein: Current Knowledge. Virol J 16: 69.

10. Yang Y, Peng F, Wang R, Yange M, Guan K, et al. (2020) The deadly coronaviruses: The 2003 SARS Pandemic and the 2020 Novel Coronavirus Epidemic in China. J Autoimmun 109: 102434.

11. Donoghue M, Hsieh F, Baronas E, Godbout K, Gosselin M, et al. (2000) A Novel Angiotensin-Converting Enzyme-Related Carboxypeptidase (ACE2) Converts Angiotensin I to Angiotensin 1-9. Circ Res 87: 1-9.

12. Yan R, Zhang Y, Li Y, Xia L, Guo Y, et al. (2020) Structural Basis for the Recognition of SARS-CoV-2 by Full-Length Human ACE2. Science 367: 1444-8.

13. Hoffmann M, Kleine-Weber H, Schroeder S, Kruger N, Herrler T, et al. (2020) SARS-CoV-2 Cell Entry Depends on ACE2 and TMPRSS2 and Is Blocked by a Clinically Proven Protease Inhibitor. Cell 181: 271-80.

14. Kumar A, Prasoon P, Kumari C, Pareek V, Faiq MA, et al. (2021) SARS-CoV-2-specific virulence factors in COVID-19. J Med Virol 3:1343-50.

15. Wrobel AG, Benton DJ, Xu P, Roustan C, Martin SR, et. al. (2020) SARS-CoV-2 and bat RaTG13 spike glycoprotein structures inform on virus evolution and furin-cleavage effects. Nat Struct Mol Biol 27: 763-7. 
16. Hart GW, Copeland RJ (2010) Glycomics hits the big time. Cell 143: 672-6.

17. Wang C, Liu Z, Chen Z, Huang X, Xu M, et al. (2020) The Establishment of Reference Sequence for SARS-CoV-2 and Variation Analysis. J Med Virol 92: 667-74.

18. Khailany RA, Safdar M, Ozaslan M (2020) Genomic Characterization of a Novel SARS-CoV-2. Gene Rep 19: 100682.

19. Ahmed SF, Quadeer AA, McKay MR (2020) Preliminary Identification of Potential Vaccine Targets for the COVID-19 Coronavirus (SARS-CoV-2) Based on SARS-CoV Immunological Studies. Viruses 12: 254

20. Amanat F, Krammer F (2020) SARS-CoV-2 Vaccines: Status Report. Immunity 52: 583-9.

21. Yoshimoto FK (2020) The Proteins of Severe Acute Respiratory Syndrome Coronavirus-2 (SARS CoV-2 or n-COV19), the Cause of COVID-19. Protein J 39: 198-216.

22. Kadam SB, Sukhramani GS, Bishnoi P, Pable AA, Barvkar VT (2021) SARS-CoV-2, the pandemic coronavirus: Molecular and structural insights. Journal of basic microbiology 61: 180-202.

23. Tay MZ, Poh CM, Renia L, MacAry PA, Ng LFP (2020) The Trinity of COVID-19: Immunity, Inflammation and Intervention. Nat Rev Immunol 20: 363-74.

24. Coutard B, Valle C, de Lamballerie X, Canard B, Seidah NG, et al. (2020) The Spike Glycoprotein of the New Coronavirus 2019nCoV Contains a Furin-Like Cleavage Site Absent in CoV of the Same Clade. Antiviral Res 176: 104742.

25. Walls AC, Park YJ, Tortorici MA, Wall A, McGuire AT, et al. (2020) Structure, Function, and Antigenicity of the SARS-CoV-2 Spike Glycoprotein. Cell 181: 281-92.

26. Bourgonje AR, Abdulle AE, Timens W, Hillebrands JL, Navis GJ, et al. (2020) Angiotensin-Converting Enzyme 2 (ACE2), SARS-CoV-2 and the Pathophysiology of Coronavirus Disease 2019 (COVID-19). J Pathol 251: 228-48.

27. Millar AH, Heazlewood JL, Giglione C, Holdsworth MJ, Bachmair A, et al. (2019) The Scope, Functions, and Dynamics of Posttranslational Protein Modifications. Annu Rev Plant Biol 70: 119-51.

28. Loboda AP, Soond SM, Piacentini M, Barlev NA (2019) Lysine-Specific Post-Translational Modifications of Proteins in the Life Cycle of Viruses. Cell Cycle 18: 1995-2005.

29. Fung TS, Liu DX (2018) Post-translational Modifications of Coronavirus Proteins: Roles and Function. Future Virol 13: 405-30.

30. Xiao X, Chakraborti S, Dimitrov AS, Gramatikoff K, Dimitrov DS (2003) The SARS-CoV S Glycoprotein: Expression and Functional Characterization. Biochem Biophys Res Commun 312: 1159-64.

31. Lin B, Qing X, Liao J, Zhuo K (2020) Role of Protein Glycosylation in Host-Pathogen Interaction. Cells 9: 1022.

32. Van Breedam W, Pohlmann S, Favoreel HW, de Groot RJ, Nauwynck HJ (2014) Bitter-Sweet Symphony: Glycan-Lectin Interactions in Virus Biology. FEMS Microbiol Rev 38: 598-632. 
33. Ritchie G, Harvey DJ, Feldmann F, Stroeher U, Feldmann H, et al. (2010) Identification of N-linked Carbohydrates from Severe Acute Respiratory Syndrome (SARS) Spike Glycoprotein. Virology 399: 257-69.

34. Walls AC, Park YJ, Tortorici MA, Wall A, McGuire AT, et al. (2020) Structure, Function, and Antigenicity of the SARS-CoV-2 Spike Glycoprotein. Cell 181: 281-92.e6.

35. Pallesen J, Wang N, Corbett KS, Wrapp D, Kirchdoerfer RN, et al. (2017) Immunogenicity and Structures of a Rationally Designed Prefusion MERS-CoV Spike Antigen. Proc Natl Acad Sci U S A 114: E7348-E57.

36. Walls AC, Xiong X, Park YJ, Tortorici MA, Snijder J, et al. (2019) Unexpected Receptor Functional Mimicry Elucidates Activation of Coronavirus Fusion. Cell 176: 1026-39 e15.

37. Zhou P, Yang XL, Wang XG, Hu B, Zhang L, et al. (2020) A Pneumonia Outbreak Associated with a New Coronavirus of Probable Bat Origin. Nature 579: 270-3.

38. Wu F, Zhao S, Yu B, Chen YM, Wang W, et al. (2020) A New Coronavirus Associated with Human Respiratory Disease in China. Nature 579: 265-9.

39. Wan Y, Shang J, Graham R, Baric RS, Li F (2020) Receptor Recognition by the Novel Coronavirus from Wuhan: an Analysis Based on Decade-Long Structural Studies of SARS Coronavirus. J Virol 94: e00127-20.

40. Chen Y, Guo Y, Pan Y, Zhao ZJ (2020) Structure Analysis of the Receptor Binding of 2019-nCoV. Biochem Biophys Res Commun 525: 135-40.

41. Wang Q, Zhang Y, Wu L, Niu S, Song C, et al. (2020) Structural and Functional Basis of SARS-CoV-2 Entry by Using Human ACE2. Cell 181: 894-904 e9.

42. Watanabe Y, Allen JD, Wrapp D, McLellan JS, Crispin M (2020) Site-Specific Glycan Analysis of the SARS-CoV-2 Spike. Science 369: 330-3.

43. Wong SK, Li W, Moore MJ, Choe H, Farzan M (2004) A 193-amino acid fragment of the SARS Coronavirus S Protein Efficiently Binds Angiotensin-Converting Enzyme 2. J Biol Chem 279: 3197-201.

44. Babcock GJ, Esshaki DJ, Thomas WD, Jr., Ambrosino DM (2004) Amino acids 270 to 510 of the Severe Acute Respiratory Syndrome Coronavirus Spike Protein Are Required for Interaction with Receptor. J Virol 78: 4552-60.

45. Varki A (2017) Biological roles of glycans. Glycobiology 27: 3-49.

46. Losfeld ME, Scibona E, Lin CW, Villiger TK, Gauss R, et al. (2017) Influence of Protein/Glycan Interaction on Site-Specific Glycan Heterogeneity. FASEB J 31: 4623-35.

47. Murray AN, Chen W, Antonopoulos A, Hanson SR, Wiseman RL, et al. (2015) Enhanced Aromatic Sequons Increase Oligosaccharyltransferase Glycosylation Efficiency and Glycan Homogeneity. Chem Biol 22: 1052-62.

48. Culyba EK, Price JL, Hanson SR, Dhar A, Wong CH, et al. (2011) Protein Native-State Stabilization by Placing Aromatic Side Chains in N-Glycosylated Reverse Turns. Science 331: 571-5. 
49. Sugrue RJ (2007) Viruses and Glycosylation: An Overview. Methods Mol Biol 379: 1-13.

50. Hoffmann M, Kleine-Weber H, Pohlmann S (2020) A Multibasic Cleavage Site in the Spike Protein of SARS-CoV-2 Is Essential for Infection of Human Lung Cells. Mol Cell 78: 779-84 e5.

51. Follis KE, York J, Nunberg JH (2006) Furin Cleavage of the SARS Coronavirus Spike Glycoprotein Enhances Cell-Cell Fusion but Does Not Affect Virion Entry. Virology 350: 358-69.

52. Behrens AJ, Vasiljevic S, Pritchard LK, Harvey DJ, Andev RS, et al. (2016) Composition and Antigenic Effects of Individual Glycan Sites of a Trimeric HIV-1 Envelope Glycoprotein. Cell Rep 14: 2695-706.

53. Francica JR, Varela-Rohena A, Medvec A, Plesa G, Riley JL, et al. (2010) Steric Shielding of Surface Epitopes and Impaired Immune Recognition Induced by the Ebola Virus Glycoprotein. PLoS Pathog 6: e1001098.

54. Gram AM, Oosenbrug T, Lindenbergh MF, Bull C, Comvalius A, et al. (2016) The Epstein-Barr Virus Glycoprotein gp150 Forms an Immune-Evasive Glycan Shield at the Surface of Infected Cells. PLoS Pathog 12: e1005550.

55. Helle F, Duverlie G, Dubuisson J (2011) The Hepatitis C Virus Glycan Shield and Evasion of the Humoral Immune Response. Viruses 3: 1909-32.

56. Sommerstein R, Flatz L, Remy MM, Malinge P, Magistrelli G, et al. (2015) Arenavirus Glycan Shield Promotes Neutralizing Antibody Evasion and Protracted Infection. PLoS Pathog 11: e1005276.

57. Walls AC, Tortorici MA, Frenz B, Snijder J, Li W, et al. (2016) Glycan Shield and Epitope Masking of a Coronavirus Spike Protein Observed by Cryo-Electron Microscopy. Nat Struct Mol Biol 23: 899-905.

58. Zhao X, Guo F, Comunale MA, Mehta A, Sehgal M, et al. (2015) Inhibition of Endoplasmic Reticulum-Resident Glucosidases Impairs Severe Acute Respiratory Syndrome Coronavirus and Human Coronavirus NL63 Spike Protein-Mediated Entry by Altering the Glycan Processing of Angiotensin I-Converting Enzyme 2. Antimicrob Agents Chemother 59: 206-16.

59. Shajahan A, Archer-Hartmann S, Supekar NT, Gleinich AS, Heiss C, et al. (2021) Comprehensive characterization of N- and O- glycosylation of SARS-CoV-2 human receptor angiotensin converting enzyme 2. Glycobiology 31: 410-24.

60. Mehdipour AR, Hummer G (2021) Dual nature of human ACE2 glycosylation in binding to SARS-CoV-2 spike. Proceedings of the National Academy of Sciences of the United States of America, 118: e2100425118.

61. Artenstein AW, Opal SM (2011) Proprotein Convertases in Health and Disease. N Engl J Med 365: 2507-18.

62. Couture F, Kwiatkowska A, Dory YL, Day R (2015) Therapeutic Uses of Furin and Its Inhibitors: A Patent Review. Expert Opin Ther Pat 25: 379-96

63. Becker GL, Sielaff F, Than ME, Lindberg I, Routhier S, et al. (2010) Potent Inhibitors of Furin and Furin-Like Proprotein Convertases Containing Decarboxylated P1 Arginine Mimetics. J Med Chem 53: 1067-75.

64. Becker GL, Lu Y, Hardes K, Strehlow B, Levesque C, et al. (2012) Highly Potent Inhibitors of Proprotein Convertase Furin as Potential Drugs for Treatment of Infectious Diseases. J Biol Chem 287: 21992-2003. 
65. Sarac MS, Cameron A, Lindberg I (2002) The Furin Inhibitor Hexa-D-Arginine Blocks the Activation of Pseudomonas Aeruginosa Exotoxin a in vivo. Infect Immun 70: 7136-9.

66. Sarac MS, Peinado JR, Leppla SH, Lindberg I (2004) Protection Against Anthrax Toxemia by Hexa-D-Arginine in vitro and in vivo. Infect Immun 72: 602-5.

67. Shulla A, Heald-Sargent T, Subramanya G, Zhao J, Perlman S, et al. (2011) A Transmembrane Serine Protease is Linked to the Severe Acute Respiratory Syndrome Coronavirus Receptor and Activates Virus Entry. J Virol 85: 873-82

68. Heurich A, Hofmann-Winkler H, Gierer S, Liepold T, Jahn O, et al. (2014) TMPRSS2 and ADAM17 Cleave ACE2 Differentially and Only Proteolysis by TMPRSS2 Augments Entry Driven by the Severe Acute Respiratory Syndrome Coronavirus Spike Protein. J Virol 88: 1293-307.

69. Bertram S, Glowacka I, Blazejewska P, Soilleux E, Allen P, et al. (2010) TMPRSS2 and TMPRSS4 Facilitate Trypsin-Independent Spread of Influenza Virus in Caco-2 Cells. J Virol 84: 10016-25.

70. Skehel JJ, Wiley DC (2000) Receptor Binding and Membrane Fusion in Virus Entry: The Influenza Hemagglutinin. Annu Rev Biochem 69: 531-69.

71. Paoloni-Giacobino A, Chen H, Peitsch MC, Rossier C, Antonarakis SE (1997) Cloning of the TMPRSS2 Gene, Which Encodes a Novel Serine Protease with Transmembrane, LDLRA, and SRCR Domains and Maps to 21q22.3. Genomics 44: 309-20

72. Sharon N (2007) Lectins: Carbohydrate-Specific Reagents and Biological Recognition Molecules. J Biol Chem 282: $2753-64$.

73. Yang RY, Rabinovich GA, Liu FT (2008) Galectins: Structure, Function and Therapeutic Potential. Expert Rev Mol Med 10: e17.

74. Mitchell CA, Ramessar K, O'Keefe BR (2017) Antiviral lectins: Selective Inhibitors of Viral Entry. Antiviral Res 142: 37-54.

75. Lau YL, Peiris JS (2005) Pathogenesis of Severe Acute Respiratory Syndrome. Curr Opin Immunol 17: 404-10.

76. Machala EA, McSharry BP, Rouse BT, Abendroth A, Slobedman B (2019) Gal Power: The Diverse Roles of Galectins in Regulating Viral Infections. J Gen Virol 100: 333-49.

77. St-Pierre C, Manya H, Ouellet M, Clark GF, Endo T, et al. (2011) Host-Soluble Galectin-1 Promotes HIV-1 Replication through a Direct Interaction with Glycans of Viral gp120 and Host CD4. J Virol 85: 11742-51.

78. Xue J, Fu C, Cong Z, Peng L, Peng Z, et al. (2017) Galectin-3 Promotes Caspase-Independent Cell Death of HIV-1-Infected macrophages. FEBS J 284: 97-113.

79. Caniglia JL, Guda MR, Asuthkar S, Tsung AJ, Velpula KK (2020) A Potential Role for Galectin-3 Inhibitors in the Treatment of COVID-19. PeerJ 8: e9392.

80. Fantini J, Di Scala C, Chahinian H, Yahi N (2020) Structural and Molecular Modelling Studies Reveal a New Mechanism of Action of Chloroquine and Hydroxychloroquine Against SARS-CoV-2 Infection. Int J Antimicrob Agents 55:105960.

81. Li F (2016) Structure, Function, and Evolution of Coronavirus Spike Proteins. Annu Rev Virol 3: $237-61$. 
82. Helenius A, Aebi M (2004) Roles of N-Linked Glycans in the Endoplasmic Reticulum. Annu Rev Biochem 73: $1019-49$.

83. Satoh T, Toshimori T, Yan G, Yamaguchi T, Kato K (2016) Structural Basis for Two-Step Glucose Trimming by Glucosidase II Involved in ER Glycoprotein Quality Control. Sci Rep 6: 20575.

84. Alonzi DS, Scott KA, Dwek RA, Zitzmann N (2017) Iminosugar Antivirals: the Therapeutic Sweet Spot. Biochem Soc Trans 45: 571-82.

85. Howe JD, Smith N, Lee MJ, Ardes-Guisot N, Vauzeilles B, et al. (2013) Novel Imino Sugar Alpha-Glucosidase Inhibitors as Antiviral Compounds. Bioorg Med Chem 21: 4831-8.

86. Ronecker S, Zimmer G, Herrler G, Greiser-Wilke I, Grummer B (2008) Formation of Bovine Viral Diarrhea Virus E1-E2 Heterodimers is Essential for Virus Entry and Depends on Charged Residues in the Transmembrane Domains. J Gen Virol 89: 2114-21.

87. Caputo AT, Alonzi DS, Marti L, Reca IB, Kiappes JL, et al. (2016) Structures of Mammalian ER Alpha-Glucosidase II Capture the Binding Modes of Broad-Spectrum Iminosugar Antivirals. Proc Natl Acad Sci U S A 113: E4630-8.

88. Moore SE, Spiro RG (1993) Inhibition of Glucose Trimming by Castanospermine Results in Rapid Degradation of Unassembled Major Histocompatibility Complex Class I Molecules. J Biol Chem 268: 3809-12.

89. Yamauchi Y, Helenius A (2013) Virus Entry at a Glance. J Cell Sci 126: 1289-95.

90. Li W, Hulswit RJG, Widjaja I, Raj VS, McBride R, et al. (2017) Identification of Sialic Acid-Binding Function for the Middle East Respiratory Syndrome Coronavirus Spike Glycoprotein. Proc Natl Acad Sci U S A 114: E8508-E17.

91. Qing E, Hantak M, Perlman S, Gallagher T (2020) Distinct Roles for Sialoside and Protein Receptors in Coronavirus Infection. mBio 11: e02764-19.

92. Baker A, Richards S-J, Guy C, Congdon TR, Hasan M, et al. (2020) The SARS-COV-2 Spike Protein Binds Sialic Acids, and Enables Rapid Detection in a Lateral Flow Point of Care Diagnostic Device. ACS Cent Sci 6: 2046-2052.

93. Valverde P, Arda A, Reichardt NC, Jimenez-Barbero J, Gimeno A (2019) Glycans in Drug Discovery. Medchemcomm 10: 167891.

94. Watanabe Y, Bowden TA, Wilson IA, Crispin M (2019) Exploitation of Glycosylation in Enveloped Virus Pathobiology. Biochim Biophys Acta Gen Subj 1863: 1480-97.

95. von Itzstein M, Wu WY, Kok GB, Pegg MS, Dyason JC, et al. (1993) Rational Design of Potent Sialidase-Based Inhibitors of Influenza Virus Replication. Nature 363: 418-23.

96. Asano N (2003) Glycosidase Inhibitors: Update and Perspectives on Practical Use. Glycobiology 13: 93R-104R.

97. Hudak JE, Bertozzi CR (2014) Glycotherapy: New Advances Inspire a Reemergence of Glycans in Medicine. Chem Biol 21: 16-37. 


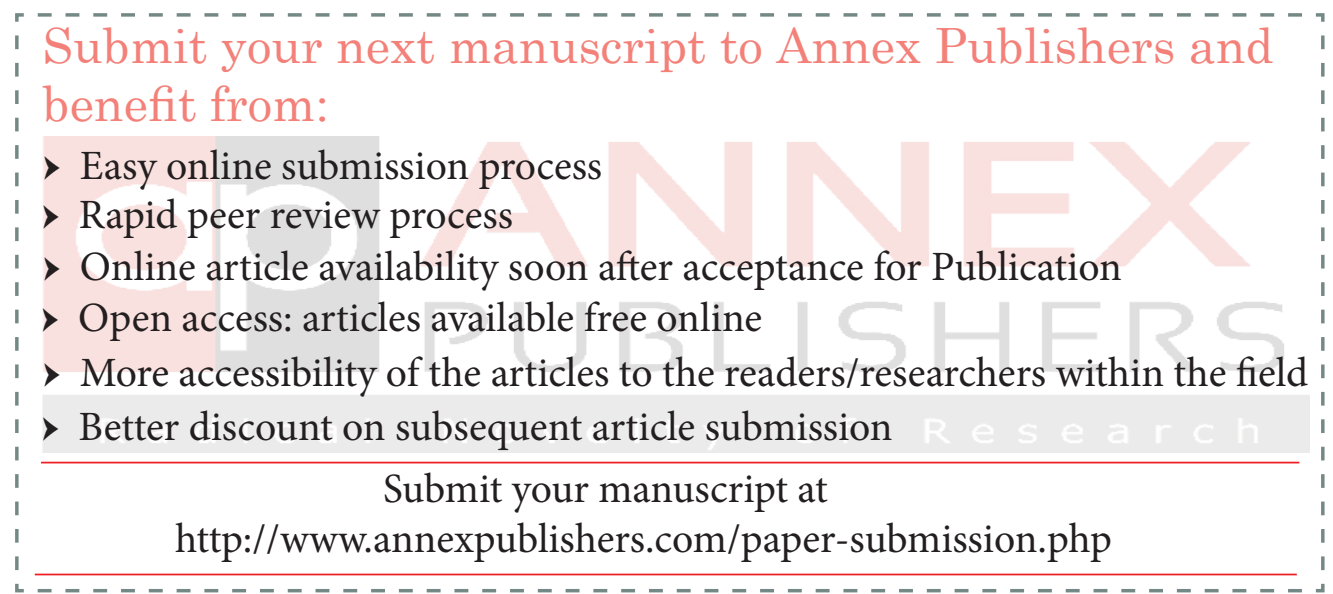

